\title{
CHEMICAL CONSTITUENTS AND CYTOTOXICITY OF SOME TANZANIAN WILD MUSHROOMS
}

\author{
V Nyigo, LD Baraza, MHH Nkunya, SJM Mdachi, CC Joseph and A Waziri \\ Department of Chemistry, University of Dar es Salaam, P.O Box 35061, \\ Dar es Salaam, Tanzania.
}

\begin{abstract}
The sterol ergosterol and ergosta-4,22-diene-3 $\beta, 7 \alpha$-diol, together with 4-hydroxybenzaldehyde were isolated from the mushroom species Polyporus molluscensis, Cantharellus isabelinus, C. symoensii and a Podaxis species. Their structures were established on the basis of spectroscopic data. The ethanol extracts of mushroom samples of Agaricus sp. and Termitomyces letestui also showed cytotoxicity against the brine shrimp larvae.
\end{abstract}

\section{INTRODUCTION}

Extensive basic and clinical research on mushrooms over the past 20 years has revealed that these fungi have an unfolding number of properties that seemingly provides remarkable health benefits (Nkunya 2002, Konno 2003). In some way, all mushrooms appear to have immunomodulatory, antiviral, antimicrobial and antitumor activities (Konno 2003). These biological activities are attributable primarily to the constituent polysaccharides (or glucans), which have different types of glycosidic linkages (Konno 2003). Some of the polysaccharides are bound to protein residues, forming polysaccharide-protein complexes. The so formed biopolymers are considered to be responsible for the immunomodulatory and anticancer properties of a wide array of mushrooms. Terpenes and steroids are also found in certain mushrooms. These compounds also have anti-inflammatory and anticancer properties (Nkunya 2002). We report the isolation and characterization of two sterols and a benzonoid from some Tanzanian mushrooms, including the cytotoxic properties of some of the crude samples in this investigation.

\section{MATERIAL AND METHODS \\ General remarks}

Mps: uncorrected. Analytical TLC was performed on precoated plates (silica gel 60 $\mathrm{F}_{254}$ Merk) using petrol-ethyl acetate as the eluent; detection by UV and anisaldehyde reagent. For column chromatography (CC) silica gel 60 (Merck) or Sephadex LH-20 (Pharmacia) were used. Vacuum liquid chromatography (VLC) was performed with silica gel (Merck) using petrol with increasing amounts of EtOAc as eluant. FTIR: KBr discs. UV spectra were obtained in $\mathrm{MeOH}$. IR spectra were recorded in $\mathrm{CHCl}_{3}$ or $\mathrm{KBr}$. NMR spectra were run in $\mathrm{CDCI}_{3}$ and $\mathrm{CD}_{3} \mathrm{COCD}_{3}$ solutions at $25^{\circ} \mathrm{C}$, $300 \mathrm{MHz}$ for ${ }^{1} \mathrm{H}$ NMR and $90 \mathrm{MHZ}$ for ${ }^{13} \mathrm{C}$ NMR. EIMS were recorded at $70 \mathrm{eV}$.

\section{Mushroom material}

The fruiting bodies used in this study were collected from Iringa, Tanga and parts of the coastal region of Tanzania. The identification was confirmed at the Herbarium of Department of Botany, University of Dar es Salaam where voucher specimens were deposited.

\section{Extraction and Isolation}

The fruiting bodies of mushroom species were oven-dried in the field, pulverized and then soaked in hexane, dichloromethane and ethanol for extraction. The filtrates were then dried on a rotary evaporator and subjected to chromatographic fractionation procedures. The crude extracts were separated by vacuum liquid chromatography (VLC) on silica gel, eluting with n-hexane containing increasing amounts of ethyl acetate. Each of the four mushroom species 
upon concentration yielded white solids in most fractions, which were purified further by recrystallization to form white needles either containing pure ergosterol (1) or mixtures of sterols. Recrystallization using ethyl acetate/pet ether of the combined $13^{\text {th }}$ and $14^{\text {th }}$ VLC fractions of Cantharellus isabelinus yielded white crystals of Ergosta4,22-diene-3 $\beta, 7 \alpha$-diol (2). The crude extract of Polyporus moluscensis was fractionated by VLC on silica gel, eluting with n-hexane containing increasing amounts of ethyl acetate, then ethyl acetate containing increasing amounts of methanol. The combined $5^{\text {th }}$ and $6^{\text {th }}$ VLC fractions of the ethanol extract, on repeated column chromatography on silica gel and further purification on Sephadex ${ }^{\circledR}$ LH-20, yielded 4-hydroxybenzaldehyde (3).

Ergosterol (1). White needles, m.p. 155$158^{\mathrm{O}} \mathrm{C}$, yield, $27 \mathrm{mg}$; anisaldehyde: Brick red; MS, m/z (rel. abundance) $396\left(\mathrm{M}^{+}\right.$, 100), 363 (85) and 337 (45).

Ergosta-4,22-diene-3 $\beta, 7 \alpha$-diol (2). White crystals, m.p. $208-220^{\circ} \mathrm{C}$, yield $7 \mathrm{mg}$; anisaldehyde: Light green; MS, $m / z$ (rel. int.); $414\left(\mathrm{M}^{+}, 3\right), 384$ (68), 379 (41), 337 (6), 269 (20) and 139 (18).

4-Hydroxybenzaldehyde (3). Brown gum, yield, $3.5 \mathrm{mg}$; anisaldehyde: Red; $\mathrm{MS}, \mathrm{m} / \mathrm{z}$ (rel. int) $122\left(\mathrm{M}^{+}\right.$80), 121 (100), 93 (45) and 65 (23); ${ }^{1} \mathrm{H}$ NMR, d 7.85 (d, J = $9 \mathrm{~Hz}$, $2 \mathrm{H}), 6.95(\mathrm{~d}, \mathrm{~J}=9 \mathrm{~Hz}, 2 \mathrm{H})$ and $9.88(\mathrm{~s}$, 1H); ${ }^{13} \mathrm{C}$ NMR, d 130.2 (C-1), 132.3 (C - 2, $\mathrm{C}-6), 115.9(\mathrm{C}-3, \mathrm{C}-5), 161(\mathrm{C}-4)$ and 190.7 (CHO).

\section{Brine Shrimp Lethality Bioassays}

The cytotoxicity of samples were tested using a test based on brine shrimp (Artemia salina Leach) larvae (Mayer 1982).

\section{RESULTS AND DISCUSSIONS}

The structures of ergosterol (1) and Ergosta4,22-diene-3 $\beta, 7 \alpha$-diol (2) and 4Hydroxybenzaldehyde (3) were established on the basis of a combination of spectroscopic analyses $\left({ }^{1} \mathrm{H}\right.$ and ${ }^{13} \mathrm{C}$ NMR, and $\mathrm{MS}$ ) and upon comparison of the observed spectral data with those reported in the literature for this or similar compounds (Chobot 1997). The MS of ergosterol (1) exhibited the $\mathrm{M}^{+}$peak at $m / z 396$ and this, as well as the ${ }^{13} \mathrm{C}$ NMR spectrum led to the deduction of the molecular formula $\mathrm{C}_{28} \mathrm{H}_{44} \mathrm{O}$. For compound 2 , the $\mathrm{M}^{+}$peak at $m / z 414$ was in agreement with the literature, hence molecular formular $\mathrm{C}_{28} \mathrm{H}_{46} \mathrm{O}_{2}$.

Both the ${ }^{1} \mathrm{H}$ and ${ }^{13} \mathrm{C}$ NMR spectra exhibited signals that were consistent with the structure of ergosterol (1). The two proton doublet of doublets at d 5.20 could be assigned to olefinic protons of the side chain at C-22 and C-23 as the signal portrayed the characteristic splitting pattern typical of olefinic proton resonances in the side chain moiety in sterols (Chobot 1997).

The ${ }^{13} \mathrm{C}$ NMR spectrum of compound $\mathbf{1}$ consisted of six signals due to $\mathrm{sp}^{2}$ carbon atoms at $\delta 141.36,139.79,135.57,132.99$, 119.59 and 116.30 , indicating the presence of three double bonds, as in ergosterol. Assignment of the rest of the ${ }^{13} \mathrm{C}$ NMR signals was made by comparison of these resonances with those reported in the literature for ergosterol (Chobot 1997).<smiles>CC(C)C(C)/C=C/C(C)[C@H]1CC[C@H]2c3ccc4c(c3CC[C@@]21C)CC[C@H](O)C4</smiles> 


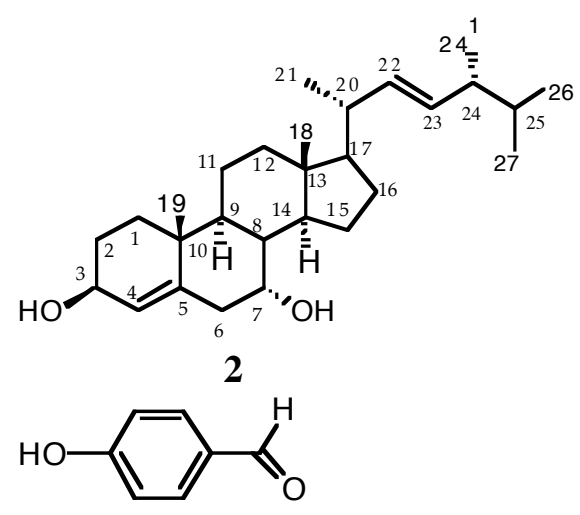

3

Both the ${ }^{1} \mathrm{H}$ and ${ }^{13} \mathrm{C}$ NMR spectra of compound 2 exhibited signals that suggested the presence of two olefinic double bonds instead of three as shown in ergosterol. The ${ }^{13} \mathrm{C}$ NMR spectrum, unlike that of ergosterol, consisted of four signals due to $\mathrm{sp}^{2}$ carbon atoms at $\delta 117.92$, $132.57,135.77$ and 144.44 , indicating the presence of two double bonds instead of three such bonds found in compound $\mathbf{1}$.

4-Hydroxybenzaldehyde was another compound obtained from Polyporus molluscensis. Quite often wild edible mushrooms possess interesting natural flavours that may be associated with low molecular weight carbonyl compounds. Therefore, 4-hydroxybenzaldehyde may be one of the compounds responsible for the natural flavour of Polyporus molluscensis. The crude extracts exhibited significant activity with brine shrimp bioassays. The value that corresponded with the lethal dose that was required to kill $50 \%$ of the the shrimp larvae was $19.54 \mathrm{mg} / \mathrm{ml}$, and 59.93 $\mathrm{mg} / \mathrm{ml}$ for ethanol extracts of Agaricus $s p$. and Termitomyces letestui respectively. The high cytotoxicity of Agaricus species suggests the reason why this mushroom is not edible in most parts of Tanzania. Further investigations need to be done to follow up the agents that are responsible for this cytotoxicity.

\section{ACKNOWLEDGEMENTS}

Financial support for this work from SIDASAREC Mushroom Project is gratefully acknowledged. We also thank L.B. Mwasumbi of the Herbarium of the University of Dar es Salaam, Department of Botany, for identification of the mushroom fruit bodies.

\section{REFERENCES}

Chobot V, Opletal L, Jahoda RL, Patel AV, Dackie GC and Blunder G 1997 Ergosta4,6,8,22-Tetraen-3-one from Edible Fungus, Pleurotus ostreatus (Oyster Fungus). Phytochemistry 45:1669-1671.

Chung R 1997 Squalene Biosynthesis. Final Research Paper for Chemistry Course at the Department of Chemistry. Cornell University, Ithaca, December 2.

Konno S 2003 Potential Supplementary Benefits from Mushrooms. PhD Thesis, New York Medical College, New York.

Mayer BN, Ferrigni NR, Putnam JE, Jacobse, IB, Nichols DE and Mc Laughlin JL 1982 Brine shrimp: A Convenient General Bioassay for Active Plant Constituents. Planta medica 31:45.

Nkunya MHH 2002 Natural Chemicals for Disease and Insect Management. Professorial Inaugural Lecture, University of Dar es Salaam, September.

Picardi SM, Issenberg P 1973 Investigation of some volatile constituents of mushrooms (Agaricus bisporus): Changes which occur during heating.. Journal of Agricultural Food Chemistry, 21:959-962.

Pyysallo H 1976 Identification of Volatile Compounds in Seven Edible Mushrooms. Acta Chemica Scandinavica B, 30:235-244. 